\title{
Smoking Prevalence and Its Clinical Correlations in Patients with Narcolepsy-cataplexy
}

\author{
Pavla Peřinová ${ }^{1}$, Eva Feketeová ${ }^{2}$, David Kemlink', Petra Kovalská', \\ Karolína Chlebušová ${ }^{1}$, Jiří Nepožitek ${ }^{1}$,Veronika Ibarburu', \\ Eva Králíková $^{3,4}$, Soňa Nevšímalová ${ }^{1}, K^{1}$ arel Šonka ${ }^{1}$ \\ ${ }^{1}$ Centre for Sleep and Wake Disorders, Department of Neurology, First Faculty \\ of Medicine, Charles University and General University Hospital in Prague, Prague, \\ Czech Republic; \\ ${ }^{2}$ Department of Neurology, Faculty of Medicine, Pavol Jozef Šafárik University \\ in Košice and Louis Pasteur University Hospital, Košice, Slovak Republic; \\ ${ }^{3}$ Institute of Hygiene and Epidemiology, First Faculty of Medicine, Charles \\ University and General University Hospital in Prague, Prague, Czech Republic; \\ ${ }^{4}$ Centre for Tobacco-Dependent, $3{ }^{\text {rd }}$ Department of Medicine - Department \\ of Endocrinology and Metabolism, First Faculty of Medicine, Charles University \\ and General University Hospital in Prague, Prague, Czech Republic
}

Received January 15, 2016; Accepted September 2, 2016.

Key words: Narcolepsy-cataplexy - Smoking - Nicotine - Etiopathogenesis Stimulating effect

Abstract: Narcolepsy-cataplexy (NC) is a chronic neurological disease with suggested autoimmune etiopathogenesis. Nicotine stimulates central nervous system and smoking increases the risk of autoimmune diseases. Assessment of smoking habits and its correlation to clinical parameters among 87 adult NC patients (38 male, 49 female) included night polysomnography and multiple sleep latency test. In our sample, $43.7 \%$ NC patients were regular smokers, and $19.5 \%$ former smokers compared to $22.2 \%$, and $12.6 \%$, respectively, in the general population. Patients started to smoke in the mean age of 20.0 (SD \pm 6.0 ) years. $72.2 \%$ of NC smokers started to smoke before the onset of $\mathrm{NC}$ and the mean of the delay between smoking onset and NC onset was $9.1( \pm 5.8)$ years. We found

This study was supported by a grant by the Ministry of Health of the Czech Republic, NF 13238-4/2012, and a grant by Charles University, PRVOUK P26/LF1/4.

Mailing Address: Prof. Karel Šonka, MD., DSc., Department of Neurology, First Faculty of Medicine, Charles University and General University Hospital in Prague, Kateřinská 30, 12000 Prague 2, Czech Republic; Phone: +420 224965 568; e-mail: ksonka@If1.cuni.cz 
a direct correlation between smoking duration and the number of awakenings, duration of N1 sleep, REM sleep latency, and apnoea/hypopnoea index (AHI), and, on the contrary, indirect correlation between smoking duration and N3 sleep duration, showing that smoking duration consistently correlates with sleep macrostructure. Smoking is highly prevalent in NC and has relationship with clinical features of NC.

\section{Introduction}

Narcolepsy-cataplexy (NC) is a chronic neurological disease with a prevalence of approximately $0.045 \%$ in North America and Europe (Ohayon et al., 2002). The manifestations of NC are excessive daytime sleepiness (EDS) and cataplexy, and roughly half of patients experience hypnagogic hallucinations and sleep paralysis. Additionally, most patients have fragmented night-time sleep. Dysregulation of REM sleep is typical, with REM sleep occurring within the first 15 minutes of sleep onset, termed sleep onset REM periods (SOREMp), during the day and at night (Dauvilliers et al., 2007). The age at onset varies from childhood to approximately 60 years of age, with manifestation most often at 15-20 years of age, and a second peak between 35 and 40 years of age (Dauvilliers et al., 2001).

The pathologic basis of the disease is a deficiency of neurons in the lateral hypothalamus that produce hypocretin (Thannickal et al., 2000). Although the exact mechanism of hypocretin deficiency is unknown, evidence from the past 20 years strongly favours an immune-mediated or autoimmune attack, targeting specifically hypocretin neurons in genetically predisposed individuals (Liblau et al., 2015). The hypothesis that a targeted immune-mediated or autoimmune attack causes the specific degeneration of hypocretin neurons arose mainly through the discovery of genetic associations, first with the HLA DQB1*06:02 allele (Mignot, 1998) and then with the T-cell receptor $\alpha$ locus (Hallmayer et al., 2009). It is suggested that specific autoimmune process is triggered by different environmental stimuli like streptococcal infection or anti H1N1 vaccination or H1N1 infection itself in genetically disposed subjects and is time limited (Partinen et al., 2014).

Dependency on tobacco is one of the most common dependencies in today's society, including the Czech Republic and Slovak Republic, with prevalence of about 30\% in the population 15-64 years (Sovinová and Csémy, 2015). Smoking as related to NC deserves our interest for several reasons. Nicotine exhibits stimulatory effects (Boutrel and Koob, 2004), so patients might use it in attempt to suppress their EDS. Some studies report that NC is associated with higher levels of impulsiveness and the so-called sensation-seeking behaviour in this condition (Dimitrova et al., 2011), which might explain increased tendency to smoke. Smoking is a risk factor for development and progression of multiple sclerosis (Carlens et al., 2010; Wingerchuk, 2012; Hedstrom et al., 2013) and other inflammatory diseases such as rheumatoid arthritis, Crohn's disease, ulcerative colitis, and 
sarcoidosis (Carlens et al., 2010). It is thus possible to assume that smoking plays a role in the development of $\mathrm{NC}$, even when smoking appears to cause multiple sclerosis in other ways than through the mediation of nicotine (Carlens et al., 2010).

This led us to find out about the proportion of our patients with NC who are smokers, and whether there is a relationship between smoking and the clinical parameters of NC.

\section{Sample and Methods}

Our study included 87 adult patients with NC we were able to contact over the course of 2015. All patients fulfilled the diagnostic criteria of the International Classification of Sleep Disorders, $2^{\text {nd }}$ Edition (ICSD2; American Academy of Sleep Medicine, 2005). The records of subjects diagnosed before 2005 (the year of ICSD2 publication) were carefully checked and conformity with ICSD2 was verified. The study included 49 women and 38 men aged from 19 to 83 years, mean age of study participants was 46.6 (SD \pm 16.3 ) years. Mean age of onset of narcolepsy symptoms was $23.5( \pm 10.4)$ years. HLA DQB1*0602 genotyping was available for 83 patients 82 of whom were positive corresponding to commonly reported representation in NC (Liblau et al., 2015). Relevant clinical data including the results of polysomnography analysed according to American Academy of Sleep Medicine (AASM) guidelines (lber et al., 2007) and Multiple Sleep Latency Test (MSLT) conducted according to AASM recommendations (Arand et al., 2005) and Epworth sleepiness scale (Johns, 1991) were completed based on patient medical records. Night polysomnography and MSLT were performed in patients who have had not been treated before or who were not taking drugs influencing sleep and $\operatorname{mood} \geq 2$ weeks.

The patients were asked about smoking according to our own structured questionnaire during their outpatient examination or in the form of phone interview. The questionnaire included the following items: classification into nonsmokers (less than 100 cigarettes in life course), former smokers and current smokers (WHO, 2008). Former and present smokers were additionally subjected to targeted questions regarding age at the first cigarette, age of regular smoking onset, number of cigarettes smoked in one day and attempts to stop smoking.

All categorical data were compared using two sided chi-squared statistics. Since polysomnographic parameters are by their nature not normally distributed, we used for inter-group comparisons Mann-Whitney U-test, other parameter were compared using parametric T-tests. Correlations were calculated as Pearson's correlations coefficients.

All statistical analyses were conducted using STATISTICA (data analysis software system), version 12. www.statsoft.com, StatSoft, Inc. (2013).

This study was part of a large study on narcolepsy approved by the Ethical Committee of the General University Hospital in Prague and all patients provided signed informed consent with this study. 


\section{Results}

Regular smokers (one or more cigarettes daily) represented $43.7 \%$ patients, while $19.5 \%$ were former regular smokers. Prevalence of smoking present in any period of life was thus $63.2 \%$ (55 patients). The patients smoked only cigarettes, no other tobacco product was recorded. Mean age at initiating smoking was $20.0( \pm 6.0)$ years and mean number of cigarettes smoked daily was $13.6( \pm 10.7)$. Forty $(72.2 \%)$ smokers started smoking prior to their first symptoms of narcolepsy, and mean recorded latency of onset of narcolepsy since smoking initiation was $9.1( \pm 5.8)$ years. Mean age of $\mathrm{NC}$ onset in patients who started smoking prior to developing $\mathrm{NC}$ was $27.8( \pm 9.0)$ years, while patients who commenced smoking after developing NC or had never smoked developed NC at $20.5( \pm 10.2)$ years of age $(p<0.001)$.

Table 1 - Clinical data on subjects suffering from NC under study expressed as mean (SD)

\begin{tabular}{llllc}
\hline & \multicolumn{1}{c}{ All } & Non-smokers & Smokers & P-value \\
\hline Number (\%) & $87.0(100)$ & $32.0(36.8)$ & $55.0(63.2)$ & NA \\
Age at smoking interview (years) & $46.6(16.3)$ & $42.2(13.8)$ & $49.1(17.2)$ & 0.043 \\
Age at NC onset (years) & $23.5(10.4)$ & $21.8(12.0)$ & $24.5(9.2)$ & NS \\
BMI & $29.2(5.1)$ & $28.3(4.5)$ & $29.7(5.4)$ & NS \\
Epworth sleepiness scale & $18.0(3.6)$ & $17.0(4.1)$ & $18.5(3.1)$ & NS \\
Number of patients with restless & $15.0(17.2)$ & $4.0(12.5)$ & $11.0(20)$ & NS \\
legs syndrome (\%) & & & & \\
Latency between night & $5.4(5.2)$ & $6.3(6.9)$ & $4.9(3.9)$ & NS \\
$\begin{array}{l}\text { polysomnography and MSLT } \\
\text { and smoking interview (years) }\end{array}$ & & & & \\
\hline
\end{tabular}

\begin{tabular}{lcrcc}
\hline \multicolumn{5}{c}{ Night polysomnography } \\
\hline Sleep efficiency (\%) & $82.6(9.9)$ & $86.0(7.8)$ & $80.7(10.2)$ & 0.022 \\
Sleep N1 duration (\%) & $11.9(9.2)$ & $9.0(6.0)$ & $13.6(10.3)$ & 0.034 \\
Sleep N2 duration (\%) & $39.0(10.8)$ & $38.6(9.6)$ & $32.3(11.4)$ & NS \\
Sleep N3 duration (\%) & $15.8(8.2)$ & $19.6(7.0)$ & $13.6(8.2)$ & 0.002 \\
REM sleep duration (\%) & $19.5(7.1)$ & $21.0(5.8)$ & $18.6(7.6)$ & NS \\
REM sleep latency (min) & $40.1(60.9)$ & $30.3(63.7)$ & $45.6(59.2)$ & NS \\
PLMI & $17.8(22.6)$ & $9.3(13.8)$ & $22.5(25.1)$ & 0.016 \\
AHI & $8.8(16.6)$ & $3.8(5.5)$ & $11.8(20.0)$ & 0.041 \\
\hline \multicolumn{7}{c}{ MSLT } & & \\
\hline Sleep latency - MSLT (min) & $2.9(2.2)$ & $2.2(1.6)$ & $3.3(2.4)$ & 0.031 \\
SOREM MSLT (number) & $3.6(1.2)$ & $3.6(1.2)$ & $3.6(1.2)$ & NS \\
\hline
\end{tabular}

Non-smokers are defined as individuals who have smoked less than 100 cigarettes in their whole life, and smokers are patients smoking at the time of questioning, taken together with those who have already quitted smoking (but had smoked more than 100 cigarettes in their life). SD - standard deviation; NA - non applicable; NC - narcolepsy with cataplexy; NS - nonsignificant; BMI - body mass index; MSLT - multiple sleep latency test; N1, N2, N3 - non rapid eye movement sleep stage 1, 2, 3 respectively; REM - rapid eye movement; PLMI - periodic leg movements index (number of periodic leg movements/1 hour); AHI - apnoea/hypopnoea index (number of apnoea/hypopnoea episodes/1 hour of sleep); SOREM - sleep onset REM period 
Relevant clinical parameters for the whole patient group and the group of smokers (i.e. former smokers and those who smoked at the time of study interview of all actively smoking taken together) and non-smokers (i.e. individuals who had smoked less than 100 cigarettes in their whole life) including statistical comparisons are shown in Table 1.

We found direct correlation between age at NC onset and the latency between onset of symptoms of narcolepsy and the age of initiating regular smoking $(0.822$, $\mathrm{p}<0.001, \mathrm{~N}=30$ ). Secondly we found negative correlation between age at NC onset and the time delay (both positive and negative) from smoking initiation to NC onset $(-0.7936, \mathrm{p}<0.001, \mathrm{~N}=45)$ in all $\mathrm{NC}$ patients.

Smoking duration correlates rather consistently with the parameters of night sleep macrostructure. We found correlation with the number of awakenings (0.5217, $p=0.001, N=39)$, duration of NREM 1 sleep $(0.3573, p<0.015, N=46)$, REM sleep latency $(0.3511, p<0.016, N=47$ ) and also $\mathrm{AHI}$ (apnoea/hypopnoea index) (0.5059, $p=0.001, N=43)$. Smoking duration was negatively correlated with sleep efficiency $(-0.5145, p<0.001, N=47)$, duration of NREM 3 sleep $(-0.6142, p<0.001$, $\mathrm{N}=46$ ). No correlation was found between smoking duration and subjective or objective evaluation of sleepiness during the day.

The number of cigarettes smoked in one day did not correlate with any NC parameter of interest.

\section{Discussion}

There are $23.5 \%$ active regular smokers in the age group of those above 15 years in the Czech Republic (Sovinová and Csémy, 2015) while the rate recorded in our sample of patients with NC was $43.7 \%$. Occurrence of active regular smoking in NC is thus twice as high as in general Czech population. A similar difference concerns the rate of former regular smoking, specifically $12.6 \%$ of former smokers in the whole Czech population against $19.5 \%$ of former regular smokers among patients with NC. Regarding the number of cigarettes smoked, our patients with NC (13.6 cigarettes daily) come close to this number in common population where regular smokers smoke around 15 cigarettes daily (Sovinová and Csémy, 2015). We assume that smoking habits are similar in Slovakia. The proportion of smokers in our NC population is about $50 \%$ higher than in an Italian study where, however, was the same percentage of smokers in the control group as is reported for the Czech population, so also the Italian study has shown higher frequency of smoking among patients with NC, the authors explain this higher rate with the stimulatory action of nicotine (Palaia et al., 2011). Higher proportion of current smokers in NC than in controls (37.2\% vs. $21.7 \%$ ) was also reported in recent large French study (Barateau et al., 2016).

Our data do not allow any conclusion regarding a possible relationship between smoking and the etiopathogenesis of narcolepsy, the differing ages of patients who started smoking prior to NC symptom onset and the age of other patients with 
$\mathrm{NC}$ is rather due to the age at NC onset than to its relationship to smoking. The relationship between smoking initiation, albeit passive, and the development of $\mathrm{NC}$ is suggested by the finding that in individuals with HLA DQB1*0602 positivity passive smoking was a risk factor of narcolepsy. The authors of this study explain why passive smoking was a risk factor, unlike active smoking, with the fact that narcolepsy symptoms in many patients begin in their childhood where exposure to active smoking is negligible (Ton et al., 2009).

Our results showing worse quality of sleep in patients with NC suggest that nicotine worsens the quality of sleep in NC as well, in the same way as in general population (Jaehne et al., 2009). The results, however, have to be taken as only approximate in this respect as smokers in our sample were older than nonsmokers, and smokers had higher AHI and PLMI (periodic leg movements index). Sleep apnoea and periodic limb movements during sleep participate in disturbing the quality of night sleep, and this is also the case in NC (Sansa et al., 2010).

In our sample, smoking duration correlated clearly with objective parameters of night sleep quality. To some degree, this might be explained with ageing the changes described develop also as a result of ageing as such (Šonka et al., 1993). This finding might also suggest that smoking has a cumulative rather than immediate effect on quality of sleep which has not been described yet and should be tested by a more elaborated study.

The fact that the number of cigarettes smoked does not correlate with subjective or objective sleepiness, may be rather interpreted as suggesting that our patients do not use cigarette smoking as self-indicated drug against EDS but this relationship is far to be excluded. Shorter mean sleep latency in MSLT in patients - non-smokers may be interpreted only with difficulty as patients undergoing MSLT are prohibited to smoke (Arand et al., 2005) and smokers should thus rather have shorter latency of falling asleep as is the case in smoking abstinence in smokers in the general population (Prosise et al., 1994). More severe sleepiness of smokers in MSLT, however, might have been influenced by worse quality night sleep related to obstructive apnoeas and periodic limb movements that may accentuate sleepiness during the day by itself, though no clear evidence for this exists in NC, unlike in general population (Engleman and Douglas, 2004; Hornyak et al., 2006). Case reports suggest that nicotine may mask or relieve symptoms of narcolepsy, including EDS and even cataplexy (Krahn et al., 2009; Ebben and Krieger, 2012). Such an interaction is supported by limited data suggesting that nicotine addiction may be mediated by hypocretin pathways (Corrigall, 2009).

Nicotine exhibits antidepressant action (Tizabi et al., 1999), so higher-degree smoking might also be related to increased prevalence of several depressive symptoms (Vourdas et al., 2002; Fortuyn et al., 2010). Higher rate of smokers among narcolepsy patients is not connected to hypocretin deficiency because from animal models it seems that hypocretin system's role is to reduce drug seeking behaviours. Hypocretin knockout mice showed reduced signs of withdrawal from 
nicotine (Plaza-Zabala et al., 2013). All other reasons possibly leading to smoking in $\mathrm{NC}$ should be tested by more sophisticated research.

Not negligible is certainly also the impact of smoking on the general health of a patient with NC. Smoking is a risk factor for many cardiovascular and metabolic diseases. Literary data and our unpublished results show that patients with NC suffer from higher rates of arterial hypertension, type 2 diabetes and obesity (Sonka et al., 2010; Jennum et al., 2013; Ohayon, 2013), which may also be related to higher rate of smoking in NC.

Although narcolepsy symptom relief may be viewed as a benefit of nicotine and may thus be a barrier to smoking cessation in narcoleptics, the act of smoking is itself of concern because of many reasons. First is the risk of falling asleep while smoking resulting in injury and damage (Krahn et al., 2009) and second is the already mentioned risk factor of many other diseases. Third reason is based on the fact that nicotine is a highly addictive substance (Benowitz, 2008), and this obviously applies to the narcolepsy population as well.

This study has several limitations that were mostly mentioned in the discussion above. The limitation is not only a small number of patients, but also the latency between complete clinical examination and interview regarding smoking, limited information about smoking and missing personality profiles of the respondents. Larger prospective studies of smoking in NC are certainly worth considering. In any case, patients with NC should be instructed not to start smoking, and if this has already happened, to quit smoking.

\section{References}

American Academy of Sleep Medicine (2005) International Classification of Sleep Disorders: Diagnostic and Coding Manual, $2^{\text {nd }}$ Ed. American Academy of Sleep Medicine, Westchester.

Arand, D., Bonnet, M., Hurwitz, T., Mitler, M., Rosa, R., Sangal, R. B. (2005) The clinical use of the MSLT and MWT. Sleep 28, 123-144.

Barateau, L., Jaussent, I., Lopez, R., Boutrel, B., Leu-Semenescu, S., Arnulf, I., Dauvilliers, Y. (2016) Smoking, alcohol, drug use, abuse and dependence in narcolepsy and idiopathic hypersomnia: a case-control study. Sleep 39, 573-580.

Benowitz, N. L. (2008) Clinical pharmacology of nicotine: implications for understanding, preventing, and treating tobacco addiction. Clin. Pharmacol.Ther. 83, 531-541.

Boutrel, B., Koob, G. F. (2004) What keeps us awake:The neuropharmacology of stimulants and wakefulnesspromoting medications. Sleep 27, 1181-1194.

Carlens, C., Hergens, M. P., Grunewald, J., Ekbom, A., Eklund, A., Hoglund, C. O., Askling, J. (2010) Smoking, use of moist snuff, and risk of chronic inflammatory diseases. Am. J. Respir. Crit. Care Med. 181, 1217-1222.

Corrigall,W.A. (2009) Hypocretin mechanisms in nicotine addiction: evidence and speculation. Psychopharmacology (Berl.) 206, 23-37.

Dauvilliers, Y., Montplaisir, J., Molinari, N., Carlander, B., Ondze, B., Besset, A., Billiard, M. (2001) Age at onset of narcolepsy in two large populations of patients in France and Quebec. Neurology 57, 2029-2033.

Dauvilliers, Y., Arnulf, I., Mignot, E. (2007) Narcolepsy with cataplexy. Lancet 369, 499-511.

Dimitrova, A., Fronczek, R., Van der Ploeg, J., Scammell, T., Gautam, S., Pascual-Leone, A., Lammers, G. J. (2011) Reward-seeking behavior in human narcolepsy. J. Clin. Sleep Med. 7, 293-300. 
Ebben, M. R., Krieger, A. C. (2012) Narcolepsy with cataplexy masked by the use of nicotine. J. Clin. Sleep Med. 8, 195-196.

Engleman, H. M., Douglas, N. J. (2004) Sleep. 4: Sleepiness, cognitive function, and quality of life in obstructive sleep apnoea/hypopnoea syndrome. Thorax 59, 618-622.

Fortuyn, H. A., Lappenschaar, M. A., Furer, J.W., Hodiamont, P. P., Rijnders, C. A. T., Renier, W. O., Buitelaar, J. K., Overeem, S. (2010) Anxiety and mood disorders in narcolepsy: a case-control study. Gen. Hosp. Psychiatry 32, 49-56.

Hallmayer, J., Faraco, J., Lin, L., Hesselson, S., Winkelmann, J., Kawashima, M., Mayer, G., Plazz, G., Nevsimalova, S., Bourgin, P., Hong, S. C., Honda, Y., Honda, M., Högl, B., Longstreth, W. T. Jr., Montplaisir, J., Kemlink, D., Einen, M., Chen, J., Musone, S. L., Akana, M., Miyagawa, T., Duan, J., Desautels, A., Erhardt, C., Hesla, P. E., Poli, F., Frauscher, B., Jeong, J. H., Lee, S. P., Ton, T. G., Kvale, M., Kolesar, L., Dobrovolná, M., Nepom, G. T., Salomon, D., Wichmann, H. E., Rouleau, G. A., Gieger, C., Levinson, D. F., Gejman, P.V., Meitinger, T., Young, T., Peppard, P., Tokunaga, K., Kwok, P.Y., Risch, N., Mignot, E. (2009) Narcolepsy is strongly associated with T-cell receptor alpha locus. Nat. Genet. 41, 708-711.

Hedstrom, K. A., Hillert, J., Olsson, T., Alfredsson, L. (2013) Smoking and multiple sclerosis susceptibility. Eur. J. Epidemiol. 28, 867-887.

Hornyak, M., Feige, B., Riemann, D., Voderholzer, U. (2006) Periodic leg movements in sleep and periodic limb movement disorder: prevalence, clinical significance and treatment. Sleep Med. Rev. 10, 169-177.

Iber, C., Ancoli-Israel, S., Chesson, A., Quan, S. F. (2007) The AASM Manual for the Scoring of Sleep and Associated Events: Rules, Terminology and Technical Specifications, $1^{\text {st }}$ Ed. American Academy of Sleep Medicine, Westchester.

Jaehne, A., Loessl, A. B., Bárkai, Z., Riemann, D., Hornyak, M. (2009) Effects of nicotine on sleep during consumption, withdrawal and replacement therapy. Sleep Med. Rev. 13, 363-377.

Jennum, P., Ibsen, R., Knudsen, S., Kjellberg, J. (2013) Comorbidity and mortality of narcolepsy: a controlled retro- and prospective national study. Sleep 36, 835-840.

Johns, M.W. (1991) A new method for measuring daytime sleepiness: the Epworth sleepiness scale. Sleep 14, 540-545.

Krahn, L. E., Martin, K. A., Silber, M. H. (2009) Narcoleptic patients' perceptions of nicotine. J. Clin. Sleep Med. 5, 390.

Liblau, R. S., Vassalli, A., Seifinejad, A., Tafti, M. (2015) Hypocretin (orexin) biology and the pathophysiology of narcolepsy with cataplexy. Lancet Neurol. 14, 318-328.

Mignot, E. (1998) Genetic and familial aspects of narcolepsy. Neurology 50, 16-22.

Ohayon, M. M. (2013) Narcolepsy is complicated by high medical a psychiatric comorbidities: a comparison with the general population. Sleep Med. 14, 488-492.

Ohayon, M. M., Priest, R. G., Zulley, J., Smirne, S., Paiva, T. (2002) Prevalence of narcolepsy symptomatology and diagnosis in the European general population. Neurology 58, 1826-1833.

Palaia, V., Poli, F., Pizza, F., Antelmi, E., Franceschini, C., Moghadam, K. K., Provini, F., Pagotto, U., Montagna, P., Schenck, C. H., Mignot, E., Plazzi, G. (2011) Narcolepsy with cataplexy associated with nocturnal compulsive behaviors: a case-control study. Sleep 34, 1365-1371.

Partinen, M., Kornum, B. R., Plazzi, G., Jennum, P., Julkunen, I., Vaarala, O. (2014) Narcolepsy as an autoimmune disease: the role of H1N1 infection and vaccination. Lancet Neurol. 13, 600-613.

Plaza-Zabala, A., Flores, A., Martín-García, E., Saravia, R., Maldonado, R., Berrendero, F. (2013) A role for hypocretin/orexin receptor-1 in cue-induced reinstatement of nicotine-seeking behavior. Neuropsychopharmacology 38, 1724-1736.

Prosise, G. L., Bonnet, M. H., Berry, R. B., Dickel, M. J. (1994) Effects of abstinence from smoking on sleep and daytime sleepiness. Chest 105, 1136-1141.

Peřinová P. et al. 
Sansa, G., Iranzo, A., Santamaria, J. (2010) Obstructive sleep apnea in narcolepsy. Sleep Med. 11, 93-95.

Šonka, K., Tafti, M., Billiard, M. (1993) Polysomnografické nálezy u narkoleptiků středního a vyššího věku. Sb. Lek. 94, 333-344.

Sonka, K., Kemlink, D., Buskova, J., Pretl, M., Srutkova, Z., Maurovich Horvat, E., Vodicka, P., Polakova, V., Nevsimalova, S. (2010) Obesity accompanies narcolepsy with cataplexy but not narcolepsy without cataplexy. Neuro Endocrinol. Lett. 31, 631-634.

Sovinová, H., Csémy, L. (2015) The Use of Tobacco and Alcohol in the Czech Republic 2014. National Institute of Public Health, Prague; available at: http://www.szu.cz/uploads/documents/czzp/zavislosti/TabAlkCZ_ EN2014.pdf

Thannickal,T. C., Moore, R.Y., Nienhuis, R., Ramanathan, L., Gulyani, S., Aldrich, M., Cornford, M., Siegel, J. M. (2000) Reduced number of hypocretin neurons in human narcolepsy. Neuron 27, 469-474.

Tizabi, Y., Overstreet, D. H., Rezvani, A. H., Louis, V. A., Clark, E. Jr., Janowsky, D. S., Kling, M. A. (1999) Antidepressant effects of nicotine in an animal model of depression. Psychopharmacology 142, 193-199.

Ton, G. N. T., Longstreth, W.T. Jr., Koepsell, T. (2009) Active and passive smoking and risk of narcolepsy in people with HLA DQB1*0602:A population-based case-control study. Neuroepidemiology 32, 114-121.

Vourdas, A., Shneerson, J. M., Gregory, C. A., Smith, I. E., King, M. A., Morrish, E., McKenna, P. J. (2002) Narcolepsy and psychopathology: Is there an association? Sleep Med. 3, 353-360.

WHO (2008) MPOWER; available at: http://www.who.int/tobacco/mpower/en/

Wingerchuk, D. M. (2012) Smoking: Effects on multiple sclerosis susceptibility and disease progression. Ther. Adv. Neurol. Disord. 5, 13-22. 